\title{
Placenta Accreta: Diagnostic Accuracy of Ultrasonography Versus MRI
}

\author{
ABDELMONEM M. MOURAD, M.D. ${ }^{\mathbf{1}}{ }^{\mathbf{2}}$; REEM A. ASHRY, M.D. ${ }^{\mathbf{2}},{ }^{\mathbf{3}}$ and SOHIR IBRAHIM, M.Sc. ${ }^{\mathbf{4}}$ \\ The Department of Radiodiagnosis, Saudi German Hospital, Riyadh, Saudi Arabia ${ }^{1}$, Department of Radiology, \\ Assiut School of Medicine, Assiut University, Egypt ${ }^{2}$, Department of Radiodiagnosis, Sulaiman Alhabib Hospital, \\ Riyadh, Saudi Arabia ${ }^{3}$ and Department of Obstetrics \& Gynecology, Saudi German Hospital, Riyadh, Saudi Arabia ${ }^{4}$
}

\begin{abstract}
Background: Placenta accreta is an aberrant attachment of the placenta within the myometrium due to the absence of decidua basalis with subsequent infiltration of the myometrium by chorionic villi.

Aim of Study: The present study aimed to construct the basic criteria of both sonographic and MRI for the diagnosis of placenta accrete and figuring out the accuracy of those criteria parallel with the definition of the most peculiar features in clinical practice.

Material and Methods: 84 pregnant women at high risk of placenta accrete occurrence from two Obstetric Centers; Saudi German and Sulaiman Alhabib Hospitals, Riyadh, KSA, have been disgnosed in the period from January 2015 to May 2017. All patients did abdominal ultrasonography and MRI to evaluate the suspected diagnosis of placenta accreta. A comparison was made between the results of both procedures and the final diagnosis that was confirmed by clinical findings at delivery and pathologic examination of specimens.
\end{abstract}

Results: No significant difference in the sensitivity and specificity of ultrasonography and MRI (sensitivity: Ultrasonography, $100 \%$ versus MRI, $76.9 \%$, specificity: Ultrasonography, $37 \%$, versus MRI, $50 \%$ ). Incongruence was found in 28 of 84 cases between ultrasonography and MRI. In these, ultrasonography was correct in 16 cases, and MRI was correct in 12 cases. This was statistically non-significant.

Conclusion: Both modalities have nearly the same diagnostic accuracy. Ultrasonography is the commonly used and the most sensitive imaging method. Moreover, MRI acts as a perfect complement method to ultrasonography in case of the presence of few inconclusive ultrasound findings.

Key Words: Ultrasonography - Placenta accreta - Magnetic resonance imaging.

Correspondence to: Dr. Abdelmonem M. Mourad, E-Mail: dr alekali@yahoo.com

\section{Introduction}

PLACENTA accreta is an aberrant attachment of the placenta within the myometrium due to the absence of decidua basalis with subsequent infiltration of the myometrium by chorionic villi. It is the commonest reason of postpartum hemorrhage with possible emergency hysterectomy. According to the degree of myometrial infiltration, placenta accreta is classified into: Placenta accreta vera; the villi are just attached to the myometrium without muscle infiltration. Placenta increta; the villi are partially infiltrating the myometrium. Placenta percreta is the most serious one, in which the villi infiltrate the whole myometrium $[\mathbf{1 , 2}]$. The placenta accreta is one of the most common causes of postpartum hemorrhage due to the aberrant attachment of the placenta to the myometrium. Hysterectomy and blood transfusion are frequently required to control bleeding and save patient's life. Many complications are related to placenta accreta either due to local infiltrative effects, postoperative complications or those arising from blood transfusion. Placenta accreta is considered a life-threatening condition and the main cause of maternal mortality, reaching up to $7 \%[3,4]$

The incidence of placenta accreta has elevated over the last ten years due to the progressively increased number of cesarean sections which raise the rate of having placenta accrete by 8 times [5] Hung et al stated that placenta previa in association with a uterine scar is an important risk factor for

\footnotetext{
Abbreviations:

US : Ultrasonography.

MRI : Magnetic Resonance Imaging.
} 
placenta accreta, however, a multivariable analysis found that placenta previa alone is a risk factor for placenta accreta, but previous uterine surgery without an associated previa was not [6]. There are many other predisposing factors for placenta accreta like asherman syndrome, prior uterine surgeries or curettage, smoking have already been mentioned and their definite contribution to the prevalence of placenta accreta remain doubtful [7,8]. Accurate prenatal diagnosis of placenta accreta gives the chance for optimal arrangement for delivery. Since the expectation of hysterectomy is made, consequently the timing and site of delivery, availability of blood and blood products and presence of expert surgical and anesthesia team can be prepared in advance [9]. The diagnosis of placenta accreta by ultrasonography and Magnetic Resonance Imaging (MRI) is basically relying on the experience of the of the radiologists for enough years. Ultrasonography is the initial modality for diagnosis of placenta accreta in about $70 \%$ of cases. Pelvic MRI is used in cases which transabdominal and transvaginal ultrasonography are an indecisive or limited evaluation of the placenta in patients with posterior placental location $[\mathbf{1 0 , 1 1 ]}$.

Objective: The present study aimed to evaluate the settled sonographic and MRI criteria for placenta accreta diagnosis, decipher the accuracy of those established criteria to determine the most proper peculiar ultrasound and MRI criteria in the clinical practice.

\section{Material and Methods}

\section{Patients:}

The present study was carried out, on 84 pregnant women suspected to have placenta accreta in the routine sonographic assessment, during the period from January 2015 to May 2017, in Saudi German Hospital and Sulaiman Alhabib Medical center, Riyadh, KSA. Moreover, the mean gestational age at which diagnosis was done was 33.46士 2.54 weeks the hospitals' institutional review boards approved this study. Both ultrasonography and MRI were done for the patients at risk of placenta accreta. Medical reports of the selected patients were used for documenting the clinical data after getting their approval. Blinded evaluation of the sonographic and MRI images were carried out by two radiologists of mostly 10 years of experience to asses the used feature that has been used for the diagnosis of placenta accreta using score criteria. The mean time interval between ultrasound and MRI was 5.2 \pm 3.47 days. The ultrasound and MRI findings were compared with the final diagnosis at delivery and the pathologic examination of the specimens had undergone hysterectomy.

\section{Inclusion criteria:}

Our study included the pregnant women with increased risk factors of placenta accreta such as history of previous cesarean deliveries, placenta previa diagnosed by ultrasonography, pregnant women with histories of dilatation and curettage, repeated caesarian deliveries, uterine surgeries, submucous fibroid, hypertension and multiparty, Asherman's syndrome, smoking and pregnant females over 35 years.

\section{Exclusion criteria:}

All contraindication of MRI study and pregnant women refused to be included in the study.

\section{Methods:}

The sonographic examination protocol: Ultrasonography and color Doppler examinations were done using GE LOGIQ 9 system with a $5-\mathrm{MHz}$ convex probe in different directions to assess placental location, homogeneity, echo pattern, outline, relation to the myometrium and the degree of penetration. The positive signs of placenta accreta were recorded such as: Absent retroplacental echo lucent zone, absence of the vesico-uterine interface, placental vascular lacunae, bulging uterine mass and increased vascularization at the space between the uterine serosa and the vesicle wall on color Doppler imaging.

\section{MRI study protocol:}

Magnetic Resonance Imaging without Gadolinium was done on a 1.5 Tesla MRI machine (Siemens Magnetom Symphony). A written consent was taken from the patient, the patient was positioned supine. A multiplanar pelvi-abdominal Imaging was achieved with an 8-channel phased array body coil. Sagittal T1-weighted fast spin-echo sequences were acquired. T2-weighted single-shot fast spin echo sequences (HASTE) were acquired in the axial, sagittal, and coronal planes with repetition/ echo times of 1000/60 milliseconds, a 256 X 70 data matrix. Slice thickness of $5 \mathrm{~mm}$, a flip angle of $150^{\circ}$ and a typical field of view $38 \mathrm{~cm}$, extended in some cases to cover the whole pregnant uterus as shown in Fig. (1).

\section{Image analysis:}

All pregnant women enrolled in the present study, including those with negative sonographic findings for placenta accrete underwent MRI. MRI signs supporting the diagnosis of placenta accrete 
were are follow: A localized myometrial disruption at the site of placentation, T2-weighted images yielded dark intraplacental bands, inhomogeneous placental signal intensity, a localized uterine bulge, loss of the vesico-placental normal interface pattern, and neovascularization.

\section{Results}

Transabdominal ultrasonography and MRI were done in 84 pregnant women with risk factors for placenta accreta. Out of them, 52 cases had adherent placenta as final diagnosis, 50 of them were proved by the findings during delivery and pathological examination in patients who had cesarean hysterectomy. Eighty-four patients had a cesarean delivery; 32 of them (38\%) have a complete cesarean delivery with easy separation of the placenta (non adherent placenta), 2 patients $(2.3 \%)$ suffered incomplete cesarean delivery through the trials of methotrexate injection, 50 patients $(59.7 \%)$ had cesarean hysterectomy, 20 of them were planned cesarean hysterectomy and 30 cases were planned cesarean delivery with postpartum hemorrhage after placental removal requiring hysterectomy as shown in (Table 1). On one side, ultrasound successfully diagnosed 52 cases of the adherent placenta and improperly diagnosed adherent placenta in 20 of 32 patients with diagnosed normal placenta. On the other side, MRI successfully diagnosed 40 of 52 cases with placenta accreta and wrongly diagnosed 16 of 32 cases of non adherent placenta as placenta accreta. Additionally, the ultrasound sensitivity for the diagnosis of placenta accreta was $100 \%$ and for MRI was $76.9 \%(p=0.03)$. Ultrasound Specificity was $37.5 \%$ and for MRI was $50 \%(p=0.6)$. The positive predictive value was $72.2 \%$ for ultrasound and $71.4 \%$ for MRI. The final diagnosis was correct in $76.2 \%$ of cases with ultrasonography and $66.7 \%$ with MRI (Table 2).

\section{Ultrasound and MRI features:}

Ultrasound features suggested placental invasion included placental vascular lacunae (46), absent retroplacental eccholucent zone (46), evident myometrial thinning (38), absence of the vesicouterine interface (30), increased vascularization at uterine serosa-bladder wall interface (22). Vertical to the uterine wall (24), bulging uterine mass (22), irregular bladder wall (20).

\section{MRI features:}

T2 weighted images revealed dark intraplacental bands (30), disturbing interface between placenta and myometrium on T2 weighted images (46), localized myometrial disruptions at the site of placentation (48), neovascularization (18), uterine bulging (24). The sensitivity and predictive values of ultrasound and MRI features are summarized in (Table 3). Congruence and incongruence between ultrasonography and MRI: Ultrasound and MRI were congruent in 56/84 (66.5\%), in 46 cases, both ultrasound and MRI correctly diagnosed the presence or absence of abnormal adherent placenta and in 10 cases both were wrong. There was incongruence between ultrasound and MRI in 28 cases, out of their sonographic diagnosis was correct in 16 cases and in 12 of them diagnosis of MRI was correct Fig. (2).

Table (1): Characteristics of high risk patients and clinical findings.

\begin{tabular}{lcl}
\hline Clinical characteristics & $\begin{array}{c}\text { No. } \\
\text { of patients }\end{array}$ & (\%) \\
\hline - Placenta previa & 56 & 67 \\
- Previous uterine operation & 67 & 79.7 \\
- Placenta previa associated & 37 & 44 \\
$\quad$ with previous uterine operation & & \\
Final diagnosis: & & \\
- Placenta accreta/increta & 32 & 38 \\
- Placenta percreta & 20 & 24 \\
- Non adherent placenta & 32 & 38 \\
$\begin{array}{l}\text { Surgical management: } \\
\text { - Completed caesarian delivery by }\end{array}$ & 32 & 38 \\
$\quad$ smoothly removable placenta & & \\
- Incomplete caesarian delivery (trial & 2 & 2.4 \\
of methotrexate) & \\
$\begin{array}{l}\text { Caesarian hysterectomy: } \\
\text { - Planned hysterectomy } \\
\text { - Planned C section (postpartum } \\
\text { hemorrhage after placental removal } \\
\text { followed by hysterectomy) }\end{array}$ & 30 \\
\hline
\end{tabular}

Table (2): Sensitivity, specificity, PPV and NPV of ultrasonography versus MRI.

\begin{tabular}{lccccc}
\hline & Sensitivity \% & Specificity \% & PPV \% & NPV \% & Exact diagnosis \\
\hline Ultrasonography & $100 \%$ & $37.5 \%$ & $72.2 \%$ & $100 \%$ & $76.2 \%$ \\
MRI & $76.9 \%$ & $50 \%$ & $71.4 \%$ & $57 \%$ & $66.7 \%$ \\
\hline
\end{tabular}


Table (3): Sensitivity, specificity and predictive values of ultrasonography and MRI features.

\begin{tabular}{|c|c|c|c|c|c|c|}
\hline Ultreasound features & $\begin{array}{c}\text { Placenta } \\
\text { accrata/percreta } \\
(\mathrm{n}=52)\end{array}$ & $\begin{array}{l}\text { Non adherent } \\
\text { placenta }(n=32)\end{array}$ & Sensitivity & Specificity & PPV & NPV \\
\hline - Placental vascular lacunae & 46 & 24 & $88.5 \%$ & $25 \%$ & $65.7 \%$ & $57.1 \%$ \\
\hline $\begin{array}{l}\text { - Absent retroplacental eccholucent } \\
\text { zone }\end{array}$ & 46 & 10 & $88.5 \%$ & $68.7 \%$ & $82.1 \%$ & $71 \%$ \\
\hline • Evident myometrial thinning & 38 & 10 & $73.7 \%$ & $68.7 \%$ & $79.2 \%$ & $61.1 \%$ \\
\hline $\begin{array}{l}\text { - Absence of the vesico uterine } \\
\text { interface }\end{array}$ & 30 & 12 & $57.69 \%$ & $62.5 \%$ & $71.4 \%$ & $47.6 \%$ \\
\hline $\begin{array}{l}\text { - Vascualization vertical to the wall of } \\
\text { the uterus }\end{array}$ & 24 & 2 & $46.15 \%$ & $93.75 \%$ & $92.3 \%$ & $51.7 \%$ \\
\hline • Bulging uterine masses & 22 & 4 & $42.31 \%$ & $87.5 \%$ & $84.6 \%$ & $48.3 \%$ \\
\hline - Vesical wall irregularity & 20 & 6 & $38.46 \%$ & $81.25 \%$ & $76.9 \%$ & $44.8 \%$ \\
\hline - MRI features & $(\mathrm{n}=52)$ & $(\mathrm{n}=32)$ & & & & \\
\hline $\begin{array}{l}\text { - Dark intra placental bands on T2 } \\
\text { weighted images }\end{array}$ & 30 & 12 & $57.69 \%$ & $62.5 \%$ & $71.4 \%$ & $47.6 \%$ \\
\hline $\begin{array}{l}\text { - Localized myometrial disruptions at } \\
\text { site of placentation }\end{array}$ & 46 & 30 & $88.5 \%$ & $6.25 \%$ & $60.5 \%$ & $18.2 \%$ \\
\hline $\begin{array}{l}\text { - Loss of normal vesico-uterine } \\
\text { interface }\end{array}$ & 16 & 4 & $30.7 \%$ & $87.5 \%$ & $80 \%$ & $43.7 \%$ \\
\hline • Evident myometrial thinning & 48 & 28 & $92.31 \%$ & $12.5 \%$ & $63.1 \%$ & $50 \%$ \\
\hline - Neovascularization & 18 & 8 & $34.61 \%$ & $75 \%$ & $69.2 \%$ & $41.4 \%$ \\
\hline - Focal uterine protrusion & 24 & 2 & 46.15 & $93.75 \%$ & $92.3 \%$ & $51.7 \%$ \\
\hline
\end{tabular}
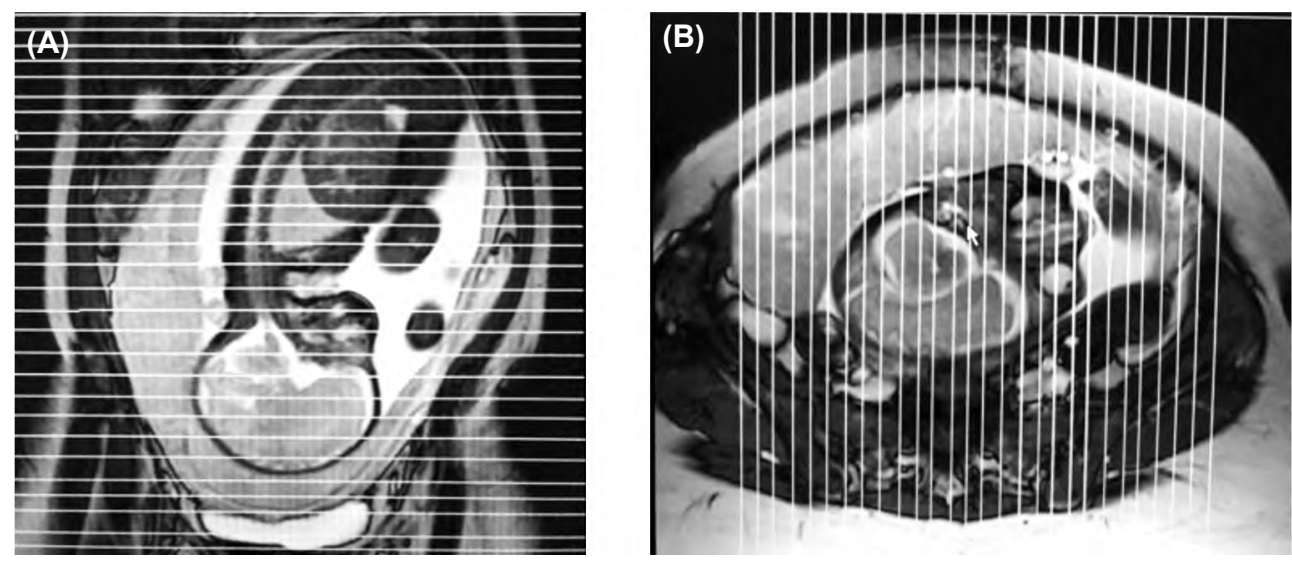

Fig. (1): MRI planes of acquisition for placenta accrete. (A) Showed the axial plane; (B) Showed the sagittal plane.

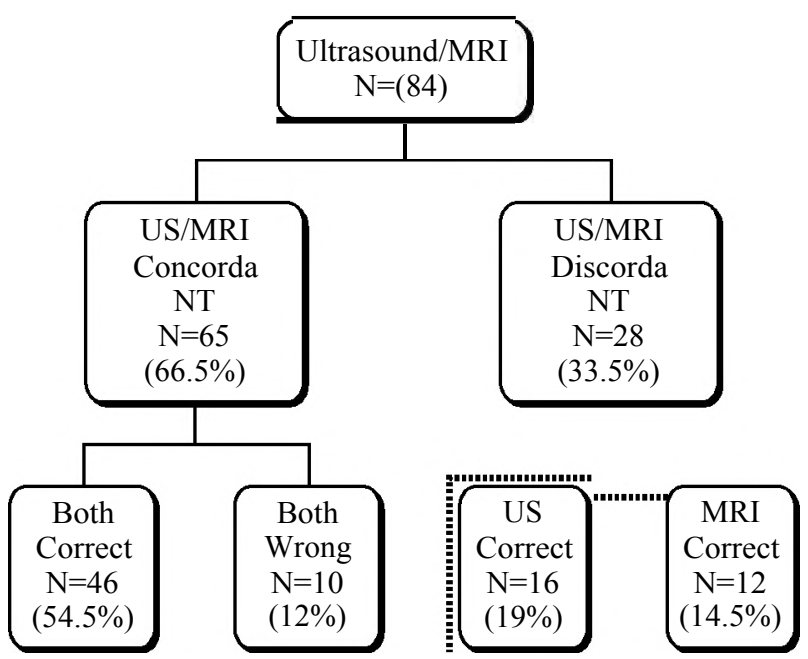

Fig. (2): Congruence and incongruence between ultrasonography and MRI in diagnosis of placenta accreta.

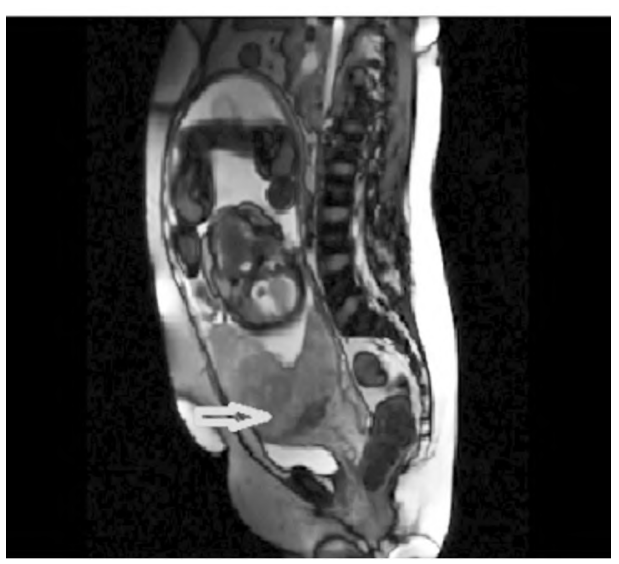

Fig. (3): Sagittal T2 WI MRI of 29 years old patients.

Showed false negative ultrasound and MRI finding, diagnosed as a placenta previa with bleeding, at surgery, persistent bleeding was found and emergency hysterectomy was performed. 


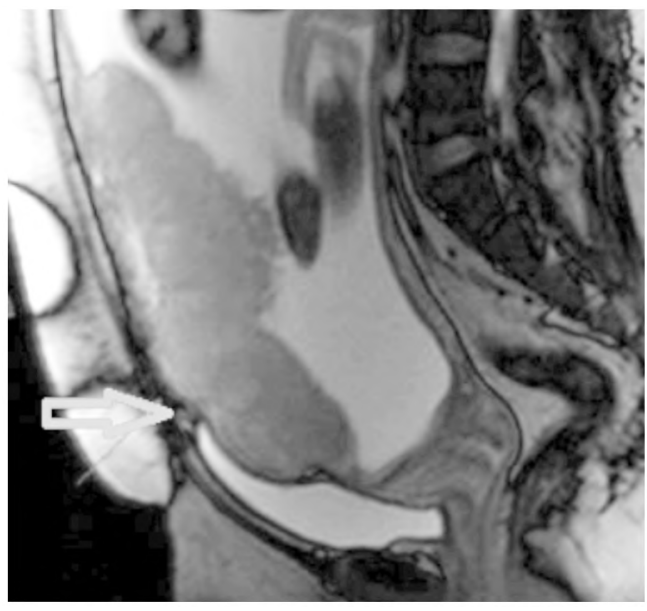

(A)

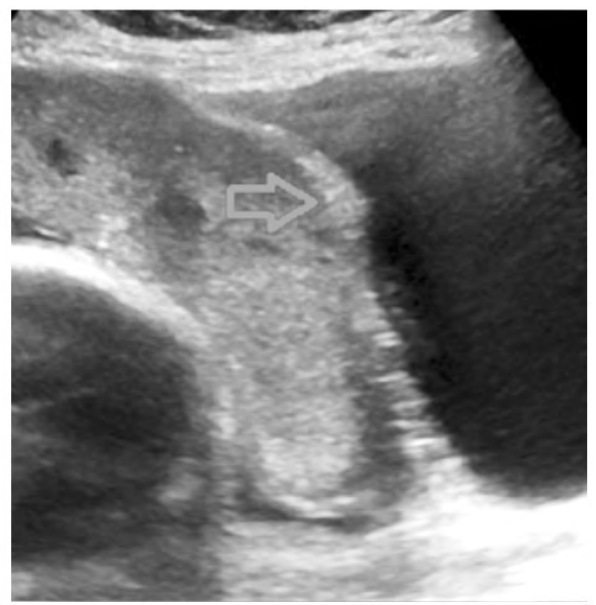

(B)

Fig. (4): Partial placenta previa in a 28-year-old woman at 34 weeks of gestation.

A- The sagittal T2 weighted image shows a uterine bulging into the bladder on MR (red arrow) with very thin uterine muscle and disrupted by placental protrusion in anterior wall lower uterine segment. B- Ultrasound revealed a focal uterine bulging disturbing the uterine serosa-bladder wall interface (red arrows).

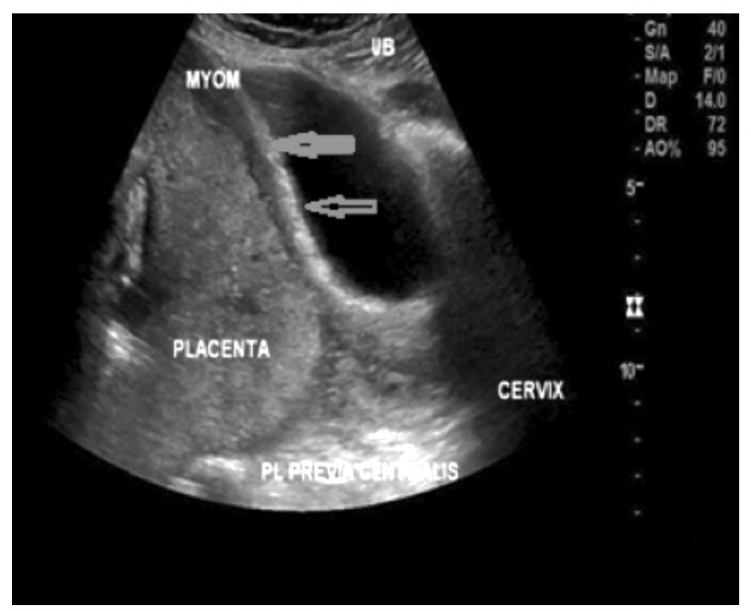

Fig. (5): Placenta accreta in a 31-year-old woman at 33 weeks of gestation.

Showed a focal loss of the normal retroplacental clear space on ultrasonography. (Bladder-wall interface) (red arrows).

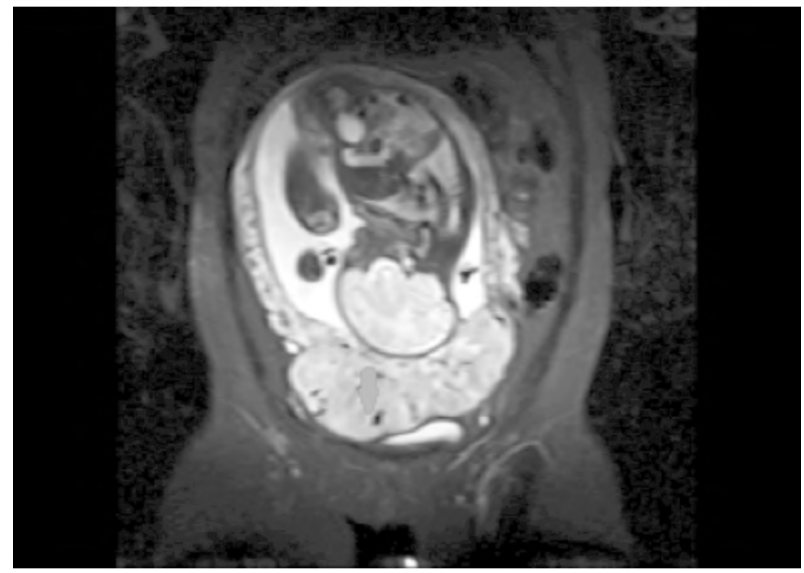

(A)

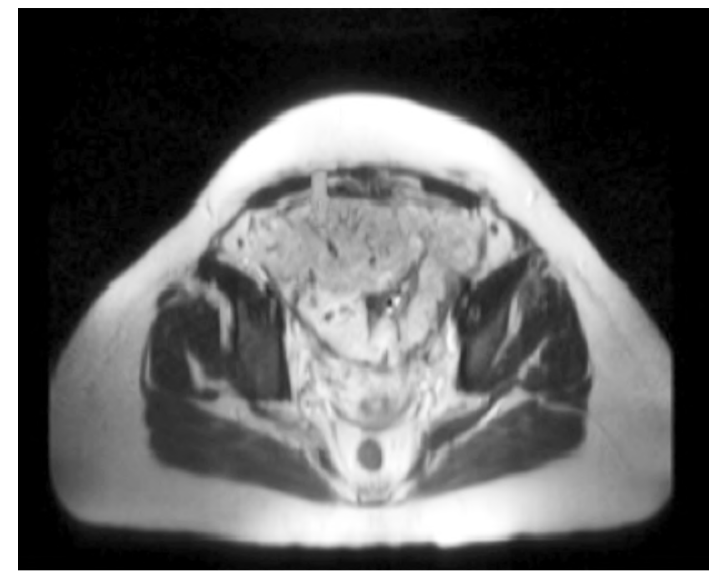

(B)

Fig. (6): Complete placenta previa in a 30-year-old woman at 36 weeks of gestation. A- Showed dark intraplacental bands on coronal and B- Axial T2-weighted images on MRI (red arrows). 

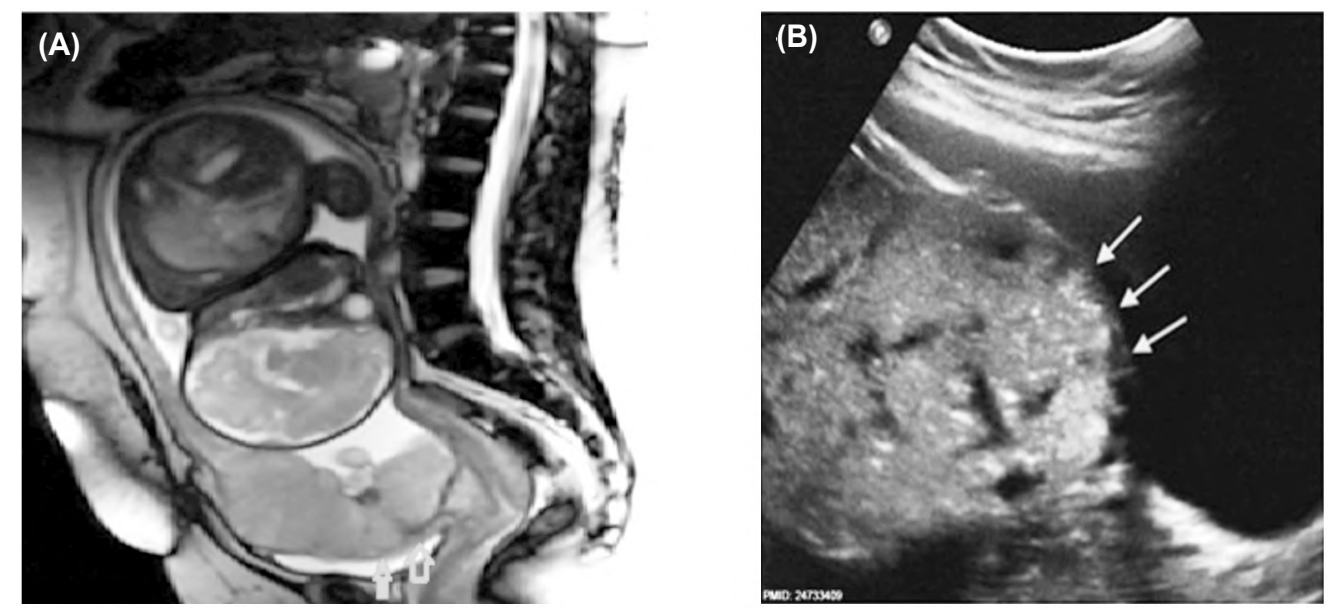

Fig. (7): A- Sagittal T2 weighted image shows loss of retroplacental clear space, invasion of the placenta accreta to myometrium and placental bulge into the bladder (red arrows). B- Is ultrasound revealed a focal uterine bulging disturbing the uterine serosa-bladder wall interface (white arrows).

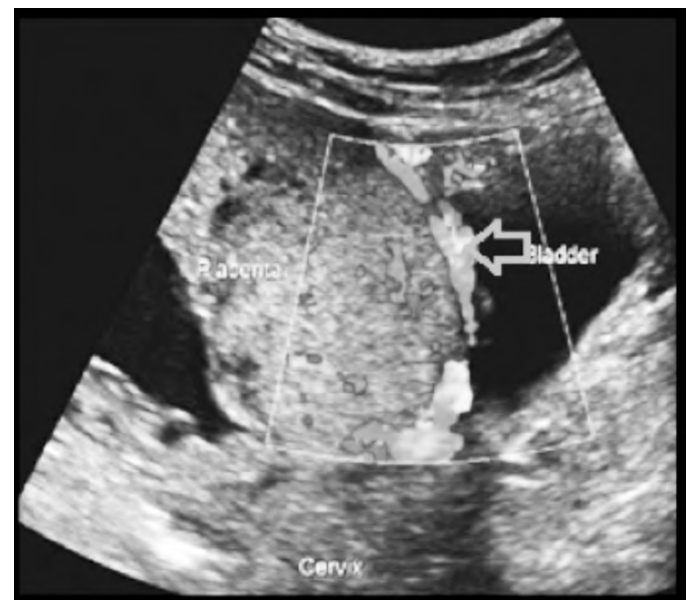

Fig. (8): Color Doppler ultrasound of placenta accreta in a 33-year-old woman at 32 weeks of gestation.

Demonstrating absence of intervening myometrium with abnormal bladder-uterine wall visualization (red arrow).

\section{Discussion}

In the present study, the final diagnosis of placental invasion of the myometrium was true in $76.2 \%$ of cases for Doppler ultrasound and in $66.7 \%$ of cases for MRI with nonsignificant difference, therefore both ultrasonography and non contrast MRI examinations have an equal diagnostic reliability for prediction of placenta accreta. Warshak and co-authors evaluated the role of ultrasonography and MRI with gadolinium for the detection of placenta accreta, and showed that the sensitivity and specificity of ultrasonography diagnosis were lower than those diagnosed with MRI with $77 \%-95 \%$ and $88 \%-100 \%$, respectively [11].

Additionally, the results were inconsistent with our study that did not show a significant statistical difference between ultrasonography and MRI. However, the usage of transvaginal ultrasound in
Warshak and co-authors study made the specificity of ultrasound better than the present study results that was not used. Whereas, other studies revealed that the sensitivity of ultrasound extends from $32 \%$ to $100 \%$ and its specificity varies from $51 \%$ to 97\% nearly [12-17]

Furthermore, the diagnostic reliability of both modalities in detecting placental invasion was considered equal by three meta analysis studies which depending upon the comparison between both modalities and recognized no significant statistical difference between the sensitivity and specificity of them, which agrees with our study as they had shown that the sensitivity of ultrasound was $91 \%$ and that of MRI was $94 \%$ and the specificity of ultrasound was $97 \%$ and that of MRI was 83.8\% [16-17]. In spite of the gadolinium-enhanced MRI study could improve its specificity in detecting placenta accreta, contrast administration in pregnancy is debatable as it crosses the placental barrier into the fetal blood. The European Society of Urogenital Radiology reported through its Safety Committee of The Contrast Media that there are no fetal side effects after using gadolinium contrast media during pregnancy, however, intravenous gadolinium should be used only in highly indicated conditions according to the American College of Radiology guidance for safe MRI practices [18]

In a case of posterior placenta, many others reported the better diagnostic outcome of MRI over ultrasound in detecting placenta accrete $[15,20,21]$. Nevertheless, in our results, we did not find a distinction between these two modalities in this case. The placental vascular lacunae are considered the most diagnostic ultrasonographic sign in several studies $[\mathbf{1 1}, \mathbf{1 4 , 1 7 , 2 2 , 2 3 ]}$. In view of our results, the sensitivity was $(88.5 \%)$, but the specif- 
icity $(25 \%)$ and PPV (65.7\%) were relatively low compared to other signs. Also, abnormal vascularization vertically to the uterine wall was one of the most distinguished sign for prediction of placenta accreta with PPV (92.3\%), sensitivity $(46.15 \%)$ and specificity $(93.75 \%)$. Other studies have documented that the sensitivity and specificity of abnormal vascularization sign are the best in the diagnosis of placental invasion, also its localization at the utero-vesical interface has the best specificity $[\mathbf{1 7 , 2 4 , 2 5 ]}$. In the present study, the sensitivity and PPV for the absence of retroplacental eccholucent margin signs are higher than those reported by others $[17,22]$.

Many studies reported that the highest positive predictive values in MRI examination are achieved in the presence of constructed association of dark intraplacental bands together with evident myometrial thinning and uterine bulging $[\mathbf{1 4 , 2 0 , 2 2 , 2 3}$, 26-29], in our study the most sensitive criteria for diagnosis of placental invasion were localized myometrial disruptions at the site of placentation, evident myometrial thinning and to less extent dark intra placental bands on T2 weighted images. On the other hand, the most specific features were a focal uterine protrusion, neovascularization and loss of the normal utero-vesico interface, this agreed with Derman and co-authors who stated that the most sensitive MR features for the detection of placental invasion were abnormal placental vascularization and intraplacental $\mathrm{T} 2$ dark bands [29].

Furthermore, investigating the same group of patients for both techniques with subsequent evaluation of the results and comparison of their accuracy gave the present study its integrity and reliability. Also, the sensitivity and specificity of MRI were evaluated without using contrast media, that is matching with most of the higher centers worldwide. One of the limitations of our study, the diagnosis of placenta accreta was depending mainly on the intraoperative findings as not all the cases had undergone pathological examination.

\section{Conclusion:}

On the principle of our study, both modalities have nearly the same diagnostic accuracy in detecting placenta accreta. However, as ultrasonography is non invasive, accurate and cheaper, it continues to be the commonly used and the most sensitive imaging method for detection of placenta accreta. MRI acts as a perfect complement to ultrasonography when there are few inconclusive ultrasound signs. Also, MRI can reveal signs not visible by ultrasonography (like intraplacental bands). On the other hand, if there are many strong sonographic signs to diagnose placenta accreta with high PPV, and MRI findings are not supporting the sonographic signs, this should not change the decision of the obstetricians.

\section{Declarations:}

Funding: This research did not receive any specific grant from funding agencies in the public, commercial, or not-for-profit sectors.

\section{Compliance with ethical standards:}

Conflict of interest: All authors declare that there is no conflict of interest.

\section{Ethical approval:}

Institutional Review Board approval was obtained for this study.

\section{Informed consent:}

Informed consent was obtained from all individual participants included in the study.

\section{Authors' contributions:}

A.M.: Designed the study, performed ultrasound examination, interpreted MRI images, analysed data, co-wrote the paper, provided critical revision of the article, provided the final approval of the paper to be published and agreed to be accountable for all aspects of the work.

R.A.: Collected data, performed ultrasound examination, interpreted MRI images, analysed data, co-wrote the paper provided and critical revision of the article, provided the final approval of the paper to be published and agreed to be accountable for all aspects of the work.

S.E.: Collected data, analysed data, cotributed to the conception and design of the study, co-wrote the paper, provided the final approval of the paper to be published and agreed to be accountable for all aspects of the work.

\section{Acknowledgement:}

We thank our colleagues from the Radiology and Obstetric Departments of the Saudi German and Soliman Alhabib hospitals, Riyadh, KSA, who assissted the research. We thank Mr. Jan Michel for his assisstance as PACS adminstrator.

\section{References}

1- BOWMAN Z.S., ELLER A.G., BARDSLEY T.R., et al.: Risk factors for placenta accrete: A large prospective Cohort. Am. J. Perinatol., Doi: 10.1055/s-0033-1361833, 2013. 
2- FITZPATRICK K.E., SELLERS S., SPARK P., et al.: Incidence and risk factors for placenta accrete/increta/ percreta in the UK: A national case-control study. PLOS ONE 7: e52893. Doi: 10.1371/journal. Pone.0052893, 2012.

3- WASHECKA R. and BEHLING A.: Urologic complications of placenta percreta invading the urinary bladder: A case report and review of the literature. Hawaii Med. J., 61: 66-9. Systematic review of case series level III, 2002.

4- O'BRIEN J.M., BARTON Jr. and DONALDSON E.S.: The management of placenta percreta: Conservative and operative strategies. Am. J. Obstet. Gynecol., 175: 16328. Case series level III, 1996.

5- WU S., KOCHERGINSKY M. and HIBBARD J.U.: Abnormal placentation: twenty-year analysis. Am. J. Obst. Gynecol., 192: 1458-61. Doi: 10.1016/j.ajog.2004. 12.074, 2005.

6- HUNG T.H., SHAU W.Y., HSIEH C.C., et al.: Risk factors for placenta accreta. Obstet. Gynecol., 93: 545-50, 1999.

7- USTA I.M., HOBEIKA E.M., MUSA A.A., et al.: Placenta previa-accreta: Risk factors and complications. Am. J. Obstet. Gynecol., 93: 1045-9, 2005.

8- MILLER D.A., CHOLLET J.A. and GOODWIN T.M.: Clinical risk factors for placenta previa/placenta accreta. Am. J. Obstet. Gynecol., 177: 210-4, 1997.

9- TIKKANEN M., PAAVONEN J., LOUKOVAARA M., et al.: Antenatal diagnosis of placenta accreta leads to reduced blood loss. Acta. Obstet. Gynecol. Scand, 90: 1140-6. Doi: 10.1111/j.1600-0412:2011. 01147, 2011.

10- COMSTOCK C.H.: Antenatal diagnosis of placenta accreta: A review. Ultrasound Obstet. Gynecol., 26: 89-96, 2005.

11- WARSHAK C.R., ESKANDER R., HULL A.D., et al.: Accuracy of ultrasonography and magnetic resonance imaging in the diagnosis of placenta accreta. Obstet. Gynecol., 108: 573-81, 2006.

12- CHOU M.M., HO E.S., LEE Y.H., et al.: Prenatal diagnosis of placenta previa accreta by transabdominal color Doppler ultrasound. Ultrasound Obstet. Gynecol., 15: 28-35, 2000.

13- DWYER B.K., BELOGOLOVKIN V., TRAN L., et al.: Prenatal diagnosis of placenta accrete: Ultrasonography or magnetic resonance imaging? J. Ultrasound Med. Sep., 27 (9): 1275-81, 2008.

14- MASSELLI G., BRUNELLI R., CASCIANI E., et al.: Magnetic resonance imaging in the evaluation of placental adhesive disorders: Correlation with color Doppler ultrasound. Eur. Radiol., 18: 1292-9, 2008.

15- LIM P.S., GREENBERG M., EDELSON M.I., et al.: Utility of ultrasound and MRI in prenatal diagnosis e not supporting the sonographic signs, this should not change the decision of the obstetricians, 2011.

16- D'ANTONIO F., IACOVELLA C. and PALACIOSJARAQUEMADA J.: Prenatal identification of invasive placentation using Magnetic Resonance Imaging. A systematic review and meta-analysis. Ultrasound Obstet. Gynecol., 2014.
17-D'ANTONIO F., IACOVELLA C. and BHIDE A.: Prenatal identification of invasive placentation using ultrasound. Systematic reviw and meta-analysis. Ultrasound Obstet. Gynecol., 42: 509-17, 2013.

18- WEBB J.A., THOMSEN H.S. and MORCOS S.K.: The use of iodinated and gadolinium contrast media during pregnancy and lactation. Members of Contrast Media Safety Committee of European Society of Urogenital Radiology (ESUR). Eur. Radiol., 15: 1234-40, 2005.

19-KANAL E., BARKOVICH A.J., BELL C., BORGSTEDE J.P., BRADLEY W.G. Jr., FROELICH J.W., et al.: ACR guidance document for safe MR practices. A.J.R. Am. J. Roentgenol., 188: 1447-74, 2007.

20- BAUGHMAN W.C., CORTEVILLE J.E. and SHAH R.R.: Placenta accreta: Spectrum of US and MRI imaging findings. Radiographics, 28: 1905-16, 2008.

21- CHOU M.M., TSENG J.J. and HO E.S.C.: The application of three-dimentional color power Doppler ultrasound in the depiction of abnormal uteroplacental angioarchitecture in placenta previa percreta. Ultrasound Obstet. Gynecol., 19: 625-7, 2002.

22- COMSTOCK C.H., LOVE J.J. Jr., BRONSTEEN R.A., LEE W., VETTRAINO I.M., et al.: Sonographic detection of placenta accreta in the second and third trimesters of pregnancy. Am. J. Obstet. Gynecol., 190: 1135-40. doi: 10.1016/j.ajog.2003.11.024, 2004.

23- FINBERG H.J. and WILLIAMS J.W.: Placenta accreta: Prospective sonographic diagnosis in patients with placenta previa and prior cesarean section. J. Ultrasound Med., 11: 333-43, 1992.

24- ELHAWARY T.M., DABEES N.L. and YOUSSEF M.A.: Diagnostic value of ultrasonography and magnetic resonance imaging in pregnant women at risk for placenta accreta. J. Matern Fetal Neonatal Med., 26: 1443-9. Doi: 10.3109/14767058.2013.784740, 2013.

25- CALÍ G., GIAMBANCO L., PUCCIO G. and FORLANI F.: Morbidly adherent placenta: Evaluation of ultrasound diagnostic criteria and differentiation of placenta accreta from percreta. Ultrasound Obstet. Gynecol., 41: 406-12. Doi: 10. 1002/uog.123 85.:10.1046/j.1469-0705.1995. 05030198.x, 2013.

26- KAYEM G., GRANGÉ G. and GOFFINET F.: [Management of placenta accreta]. Gynecol. Obstet. Fertil, 35: 186-92. Doi: 10.1016/j.gyobfe.2007.01.021, 2007.

27- LERNER J.P., DEANE S. and TIMOR-TRITSCH I.E.: Characterization of placenta accreta using transvaginal sonography and color Doppler imaging. Ultrasound Obstet. Gynecol., 5: 198-201, 1995.

28- THORP J.M. Jr., COUNCELL R.B., SANDRIDGE D.A. and WIEST H.H.: Antepartum diagnosis of placenta previa percreta by magnetic resonance imaging. Obstet. Gynecol., 80: 506-8, 1992.

29- DERMAN A.Y., NIKAC V., HABERMAN S., ZELENKO N., OPSHA O., et al.: MRI of placenta accreta: A new imaging perspective. A.J.R. Am. J. Roentgenol., 197: 1514-21. Doi: 10.2214/AJR.10.5443, 2011. 


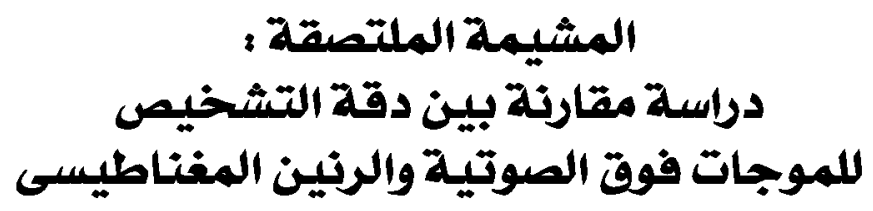

تهدف هذه الدراسة إلى تحديد المعايير الأساسية لكل من التصوير بالموجات فوق الصوتية والتصوير بالرنين المغناطيسى لتشخيص

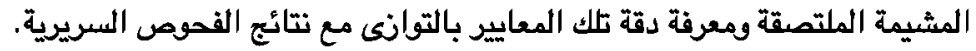
تمت الدراسة على ع^ إمرأة حامل تم تثخيصها المبدنى بوجود احتمال كبير من حدوث المشيمة الملتصقة، جميع المرضى قاموا بإجراء فحص بالموجات فوق الصوتية على البطن والرنين المغناطيسى ثم تم إجراء مقارنة بين نتائجها والتشخيص الثئ النهائى الذى أكدته النتائع السريرية عند الولادة وفحص الأنسجة للعينات.

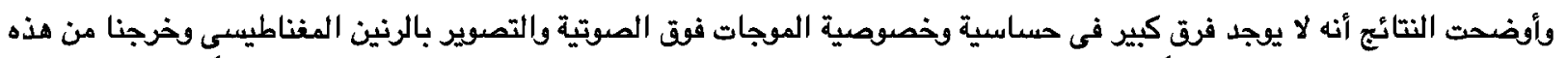
الدراسة بأن كلتا الطريقتين لديها تقريباً نفس دقة التشخيص. التصوير بالموجات فوق الصوتية هو الأسلوب الاكثر استخداماً والاكثر حساسية.

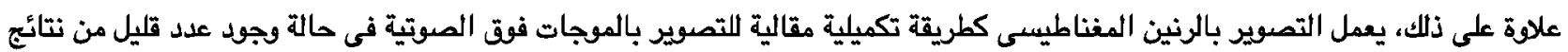
الموجات فوق الصوتية الغير حاسمة. 